\title{
Methylenetetrahydrofolate reductase polymorphisms in myeloid leukemia patients from Northeastern Brazil
}

\author{
Cynara Gomes Barbosa ${ }^{1}$, Claudio Lima Souza ${ }^{1}$, José Pereira de Moura Neto ${ }^{1}$, Maria da Glória Bomfim \\ Arruda $^{3}$, José Henrique Barreto ${ }^{4}$, Mitermayer Galvão Reis ${ }^{1}$ and Marilda Souza Goncalves ${ }^{1,2}$ \\ ${ }^{1}$ Centro de Pesquisa Gonçalo Moniz, Fundação Oswaldo Cruz, Salvador, BA, Brazil. \\ ${ }^{2}$ Faculdade de Farmácia, Universidade Federal da Bahia, Salvador, BA, Brazil. \\ ${ }^{3}$ Departamento de Hematologia, Faculdade de Medicina Edgard Santos, Hospital Universitário, \\ Universidade Federal da Bahia, Salvador, BA, Brazil. \\ ${ }^{4}$ Clinica Oncológica, Salvador, Bahia, Brazil.
}

\begin{abstract}
Methylenetetrahydrofolate reductase (MTHFR: EC 1.5.1.20) polymorphisms are associated to acute lymphoid leukemia in different populations. We used the polymerase chain reaction and the restriction fragment length polymorphism method (PCR-RFLP) to investigate MTHFR C677T and A1298C polymorphism frequencies in 67 patients with chronic myeloid leukemia (CML), 27 with acute myeloid leukemia FAB subtype M3 (AML-M3) and 100 apparently healthy controls. The MTHFR mutant allele frequencies were as follows: $\mathrm{CML}=17.2 \%$ for C677T, $21.6 \%$ for A1298C; AML-M3 $=22.2 \%$ for C677T, $24.1 \%$ for A1298C; and controls $=20.5 \%$ for C677T, $21 \%$ for A1298C. Taken together, our results provide evidence that MTHFR polymorphisms have no influence on the development of CML or AML-M3.
\end{abstract}

Key words: AML, CML, MTHFR polymorphisms.

Received: March 29, 2007; Accepted: December 7, 2007.

Leukemias are clonal diseases which commonly arise as a result of genetic damage deregulating blood cell development or hematopoiesis. The risk of leukemia may be increased by both quantitative and qualitative changes in folate metabolism (Hur et al., 2006). Methylenetetrahydrofolate reductase (MTHFR: EC 1.5.1.20) is a key enzyme in folate and homocysteine (Hcy) metabolism which catalyzes the reduction of 5,10-methylenetetrahydrofolate to 5-methylenetetrahydrofolate, the predominant circulatory form of folate and carbon donor for the remethylation of homocysteine to methionine (Skibola et al., 1999). Various studies have described an association between the presence of the C677T and A1298C MTHFR polymorphisms and the risk of leukemias (Skibola et al., 1999; Franco et al., 2001; Wiemels et al., 2001; Moon et al., 2007; Zanrosso et al., 2006), suggesting that alteration of folate metabolism in the presence of enzyme variant forms can protect against acute lymphoid leukemia (ALL) but increase the risk of chronic myeloid leukemia (CML). However, this association was not related to acute myeloid

Send correspondence to Marilda Souza Goncalves. Centro de Pesquisa Gonçalo Moniz, Fundação Oswaldo Cruz, Rua Waldemar Falcão 121, Brotas, 40296-710 Salvador, BA, Brazil. E-mail: mari@cpqgm.fiocruz.br. leukemia (AML) in British (Skibola et al., 1999) and Spanish populations (Bolufer et al., 2007).

Folate deficiency has been associated with uracil misincorporation into DNA, increasing the risk of chromosomal aberrations and presumably the onset of the leukemogenic process (Wiemels et al., 2001).

We investigated the MTHFR C677T and A1298C polymorphism frequency among AML-M3 and CML patients from Salvador in the Northeastern Brazilian state of Bahia. The frequency of these polymorphisms vary according to the population, being less common among Africans at $1.6 \%$ for $677 \mathrm{TT}$ and $4.4 \%$ for $1298 \mathrm{CC}$ (Gueant-Rodriguez et al., 2006) than in other ethnic groups such as Caucasians in which the frequency is $12.3 \%$ for $677 \mathrm{TT}$ and $11 \%$ for 1298CC (Skibola et al., 1999).

We carried out a cross-sectional study of 94 patients with myeloid leukemia, of which 67 (30 (45.5\%) female and 36 male (54.5\%); median age $44 \mathrm{y}$, range $09 \mathrm{y}$ to $93 \mathrm{y}$ ) had chronic myeloid leukemia (CML) and 27 (15 female (53.6\%) and 13 male (46.4\%); median age $27 \mathrm{y}$, (range $06 \mathrm{y}$ to $70 \mathrm{y}$ ) with acute myeloid leukemia FAB subtype M3 (AML-M3) selected between 1999 and 2003 from several institutions treating patients with malignant diseases, the institutions being: Oncology Clinic; San Raphael Hospital; 
Edgard Santos Federal University Hospital and Cehon Clinic. All these institutions are in the city of Salvador, Bahia, Brazil. The control group consisted of 100 (47 female (47\%) and 53 male (53\%); median age $29 \mathrm{y}$, range $18 \mathrm{y}$ to $40 \mathrm{y}$ ) apparently healthy individuals randomly chosen from the general population. All individuals included in this study were from Bahia, Brazil, a state which has a highly mixed population, mainly of African origin. The study was approved by the Oswaldo Cruz Research Foundation's human research ethics Committee. Bone marrow and peripheral blood samples were taken only after signed informed consent forms were obtained from patients or an official responsible.

We isolated DNA and RNA from bone marrow cells or peripheral blood leukocytes, using Trizol $^{\mathrm{R}}$ (Gibco-BRL, USA) for RNA extraction and a Genomic Blood DNA Purification Kit (Amersham Pharmacia Biotech, USA) according to the guidelines of the manufacturer. The translocations $\mathrm{t}(9 ; 22)(\mathrm{q} 34 ; \mathrm{q} 11)$ for CML patients and $\mathrm{t}(15 ; 17)$ (q22;q12-21) for AML-M3 were investigated using reverse transcriptase PCR (RT-PCR) as previously described (Borrow et al., 1992; Artigas et al., 2002).

The MTHFR C677T and A1298C polymorphisms were investigated using the polymerase chain reaction and restriction fragment length polymorphism (PCR-RFLP) technique and the Hinf I and Mbo II restriction enzymes (New England Biolabs, USA) (Wiemels et al., 2001).

Descriptive analyses included gene and allelic frequencies and we also calculated the odds ratio (OR) as an estimate of relative risk and the $95 \%$ confidence interval (CI). Moreover, the Hardy-Weinberg equilibrium was tested. Significance was considered for $\mathrm{p}<0.05$. All analyses were carried out using the EPI INFO software, version 6.04 , that is a public domain software produced by the Cen- ters for Disease Control (CDC) and the World Health Organization (WHO).

All 67 CML patients had $\mathrm{t}(9 ; 22)(\mathrm{q} 34 ; \mathrm{q} 11)$ translocations and all 27 AML-M3 patients had $\mathrm{t}(15 ; 17)$ (q22;q11-21) translocations. The total MTHFR mutant allele frequencies were as follows: $\mathrm{CML}=17.2 \%$ for $\mathrm{C} 677 \mathrm{~T}$, $21.6 \%$ for A1298C; AML-M3 = 22.2\% for C677T, 24.1\% for $\mathrm{A} 1298 \mathrm{C}$; and controls $=20.5 \%$ for $\mathrm{C} 677 \mathrm{~T}, 21 \%$ for A1298C. The C677T and A1298C polymorphism frequency distributions were in agreement with the HardyWeinberg equilibrium.

The MTHFR C677T and A1298C polymorphisms showed a similar distribution for the heterozygous and homozygous genotypes among the leukemia (CML and AML-M3) and control groups (Table 1). The double heterozygous frequencies for both MTHFR polymorphisms was $6.4 \%$ in the leukemia group and $5.0 \%$ in control groups. There was no double homozygous for both polymorphisms (Table 2).

The MTHFR enzyme and its involvement in folate metabolism have been considered a cancer susceptibility factor and the presence of the MTHFR polymorphism has been associated to DNA hypomethylation and chromosomal breaks and damage (Krajinovic et al., 2004). Skibola et al (1999) showed that variant MTHFR genotypes, including $677 \mathrm{TT}, 1298 \mathrm{AC}$ or $1298 \mathrm{CC}$ have a lower risk of developing acute lymphoid leukemia (ALL) in adulthood although it did not influence AML patients of the same age. Their observation was supported by subsequent studies performed in childhood AML (Wiemels et al., 2001). However, a similar study carried out among a highly mixed population of Brazilian leukemia patients reported the opposite effect for the A1298C polymorphism, which was associated with an elevated risk factor for non-white AML children which could also be associated with the high

Table 1 - Methylenetetrahydrofolate reductase gene (MTHFR) C677T and A1298C polymorphisms genotype distributions among 67 patients with chronic myeloid leukemia (CML), 27 with acute myeloid leukemia FAB subtype M3 (AML-M3) and 100 apparently healthy controls. The odds ratio (OR) column shows the $95 \%$ confidence interval in parentheses.

\begin{tabular}{|c|c|c|c|c|c|}
\hline \multirow{2}{*}{$\begin{array}{l}\text { MTHFR } \\
\text { polymorphisms }\end{array}$} & \multicolumn{3}{|c|}{ Number of individuals (\%) } & \multicolumn{2}{|c|}{ Odds ratio $(95 \% \mathrm{CI})$} \\
\hline & AML-M3 (\%) & CML (\%) & Controls (\%) & AML-M3 vs. controls & CML vs. controls \\
\hline \multicolumn{6}{|l|}{ C677T } \\
\hline $\mathrm{CC}$ & $17(63.0)$ & $46(68.7)$ & $65(65.0)$ & $1.0^{\mathrm{a}}$ & $1.0^{\mathrm{a}}$ \\
\hline $\mathrm{CT}$ & $8(29.6)$ & $19(28.3)$ & $29(29.0)$ & $1.03(0.37$ to 2.85$)$ & 0.97 (0.46 to 2.03$)$ \\
\hline TT & $2(7.4)$ & $2(3.0)$ & $6(6.0)$ & $1.25(0.16$ to 7.55$)$ & $0.48(0.07$ to 2.76$)$ \\
\hline $\mathrm{CT}+\mathrm{TT}$ & $10(37.0)$ & $21(31.3)$ & $35(35.0)$ & $1.09(0.41$ to 2.87$)$ & $0.85(0.42$ to 1.73$)$ \\
\hline \multicolumn{6}{|l|}{ A1298C } \\
\hline AA & $15(55.6)$ & $41(61.1)$ & $63(63.0)$ & $1.0^{\mathrm{a}}$ & $1.0^{\mathrm{a}}$ \\
\hline $\mathrm{AC}$ & $11(40.7)$ & $23(34.3)$ & $32(32.0)$ & $1.46(0.56$ to 3.81$)$ & $1.11(0.55$ to 2.25$)$ \\
\hline $\mathrm{CC}$ & $1(3.7)$ & $3(4.6)$ & $5(5.0)$ & $0.73(0.03$ to 6.97$)$ & $0.89(0.16$ to 4.48$)$ \\
\hline $\mathrm{AC}+\mathrm{CC}$ & $12(44.4)$ & $26(38.8)$ & $37(37.0)$ & $1.36(0.53$ to 3.50$)$ & $1.08(0.54$ to 2.14$)$ \\
\hline
\end{tabular}

${ }^{\mathrm{a}}$ Reference group $(\mathrm{OR}=1.0)$. 
Table 2 - Methylenetetrahydrofolate reductase gene (MTHFR) C677T and A1298C polymorphisms genotypic distributions in 94 patients (67 with chronic myeloid leukemia and 27 with acute myeloid leukemia FAB subtype M3) and 100 apparently healthy controls.

\begin{tabular}{ccccc}
\hline \multicolumn{2}{c}{ MTHFR polymorphisms } & & \multicolumn{2}{c}{ Number of individuals (\%) } \\
\cline { 1 - 2 } MTHFR C677T & MTHFR A1298C & & Leukemia patients & Controls \\
\hline CC & AA & & $34(36.0)$ & $33(33.0)$ \\
CC & AC & & $29(30.8)$ & $27(27.0)$ \\
CC & CC & & $2(2.1)$ & $5(5.0)$ \\
CT & AA & AC & $17(18.1)$ & $24(24.0)$ \\
CT & CC & & $6(6.4)$ & $5(5.0)$ \\
CT & AA & & $4(2.1)$ & 0 \\
TT & AC & & - & $6(6.0)$ \\
TT & CC & - & - \\
TT & & $94(100)$ & $100(100)$ \\
\hline Total & & & \\
\hline
\end{tabular}

frequency of malnutrition and lower socioeconomic status of African descendants in Brazil (da Costa Ramos et al., 2006). A sample population $(n=6,864)$ from Northeastern Brazilian showed an estimated $97 \%$ interethnic panmixia, possibly due to the intensive African slave trade when more than five million people from several African countries were brought to Brazil between 1550 and 1850, principally between the eighteenth and nineteenth centuries (Krieger et al., 1965). However, Chiusolo et al (2004) found no evidence of an association between the MTHFR C677T and A1298C genotypes and susceptibility to ALL among Italian patients.

Our present findings demonstrate a similar MTHFR polymorphism frequency distribution among CML and AML-M3 patients and controls, while Hur et al. (2006) demonstrated a significant decrease in CML risk among Koreans with the A1298C polymorphism. These differences indicate the possible influence of racial, ethnic and nutritional factors in several population groups and the MTHFR polymorphisms in the relationship between MTHFR polymorphisms and leukemia (Zanrosso et al., 2006). Moreover, lymphoid cells may require more folate and be more susceptible to folate deficiency, resulting in higher DNA damage in this lineage than in myeloid cells (Skibola et al., 1999).

The MTHFR polymorphism frequencies described here, together with the absence of double homozygotes for the $\mathrm{C} 677 \mathrm{~T} / \mathrm{A} 1298 \mathrm{C}$ mutations, suggest the rarity of these mutations in cis which are probably incompatible with fetus development (Skibola et al., 1999; Chiusolo et al., 2004; Zanrosso et al., 2006).

In conclusion, we found no association between the MTHFR C677T and A1298C polymorphisms among AML-M3 and CML patients from the Northeastern Brazilian state of Bahia. Therefore, further studies are necessary to consider the interaction of folate nutritional status and genes associated to folate metabolism, in order to establish its role in leukemogenesis.

\section{Acknowledgments}

Financial support was provided by the Brazilian agency FAPESB (grant number 277/04).

\section{References}

Artigas CG, Melo A, Roa JC, Paez E, Vittini C, Arriagada M, Gonzalez L, Pflaumer E and Roa I (2002) Detection of BCR-ABL gene sequences using RT-PCR in patients with leukemia in the IX region. Rev Med Chil 130:623-630.

Bolufer P, Collado M, Barragan E, Cervera J, Calasanz MJ, Colomer D, Roman-Gomez J and Sanz MA (2007) The potential effect of gender in combination with common genetic polymorphisms of drug-metabolizing enzymes on the risk of developing acute leukemia. Haematologica 92:308-314.

Borrow J, Goddard AD, Gibbons B, Katz F, Swirsky D, Fioretos T, Dube I, Winfield DA, Kingston J and Hagemeijer A (1992) Diagnosis of acute promyelocytic leukaemia by RTPCR: Detection of PML-RARA and RARA-PML fusion transcripts. Br J Haematol 82:529-540

Chiusolo P, Reddiconto G, Cimino G, Sica S, Fiorini A, Farina G, Vitale A, Sora F, Laurenti L, Bartolozzi F et al. (2004) Methylenetetrahydrofolate reductase genotypes do not play a role in acute lymphoblastic leukemia pathogenesis in the Italian population. Haematologica 89:139-144.

da Costa Ramos FJ, Cartaxo Muniz MT, Silva VC, Araújo M, Leite EP, Freitas EM, Zancorosso CW, Hatagima A, de Mello MP, Yunes JÁ et al. (2006) Association between the MTHFR A1298C polymorphism and increased risk of acute myeloid leukemia in Brazilian children. Leuk Lymphoma 47:2070-2075.

Franco RF, Simoes BP, Tone LG, Gabellini SM, Zago MA and Falcao RP (2001) The methylenetetrahydrofolate reductase C677T gene polymorphism decreases the risk of childhood acute lymphocytic leukaemia. Br J Haematol 115:616-618.

Gueant-Rodriguez RM, Gueant JL, Debard R, Thirion S, Hong LX, Bronowicki JP, Namour F, Chabi NW, Sanni A, Anello $\mathrm{G}$ et al. (2006) Prevalence of methylenetetrahydrofolate 
reductase $677 \mathrm{~T}$ and $1298 \mathrm{C}$ alleles and folate status: A comparative study in Mexican, West African, and European populations. Am J Clin Nutr 83:701-707.

Hur M, Park JY, Cho HC, Lee KM, Shin HY and Cho HI (2006) Methylenetetrahydrofolate reductase A1298C genotypes are associated with the risks of acute lymphoblastic leukaemia and chronic myelogenous leukaemia in the Korean population. Clin Lab Haematol 28:154-159.

Krajinovic M, Lamothe S, Labuda D, Lemieux-Blanchard E, Theoret Y, Moghrabi A and Sinnett D (2004) Role of MTHFR genetic polymorphisms in the susceptibility to childhood acute lymphoblastic leukemia. Blood 103:252257.

Krieger H, Morton NE, Mi MP, Azevedo E, Freire-Maia A and Yasuda N (1965) Racial admixture in north-eastern Brazil. Ann Hum Genet 29:113-125.

Moon HW, Kim TY, Oh BR, Min HC, Cho HI, Bang SM, Lee JH, Yoon SS and Lee DS (2007) MTHFR 677CC/1298CC geno- types are highly associated with chronic myelogenous leukemia: A case-control study in Korea. Leuk Res 31:12131217.

Skibola CF, Smith MT, Kane E, Roman E, Rollinson S, Cartwright RA and Morgan G (1999) Polymorphisms in the methylenetetrahydrofolate reductase gene are associated with susceptibility to acute leukemia in adults. Proc Natl Acad Sci 96:12810-12815.

Wiemels JL, Smith RN, Taylor GM, Eden OB, Alexander FE and Greaves MF (2001) Methylenetetrahydrofolate reductase (MTHFR) polymorphisms and risk of molecularly defined subtypes of childhood acute leukemia. Proc Natl Acad Sci 27:4004-4009.

Zanrosso CW, Hatagima A, Emerenciano M, Ramos F, Figueiredo A, Felix TM, Segal SL, Giugliani R, Muniz MT and Pombo-de-Oliveira MS (2006) The role of methylenetetrahydrofolate reductase in acute lymphoblastic leukemia in a Brazilian mixed population. Leuk Res 30:477-481.

Associate Editor: Francisco Mauro Salzano 